\title{
DESEMPENHO DE CORDEIROS CRUZADOS EM ALAGOAS, BRASIL*
}

\author{
PERFORMANCE OF THE CROSSBREED LAMBS IN ALAGOAS, BRASIL
}

\author{
Rocha, L.P. ${ }^{1}$, A.B. Fraga ${ }^{2 A}$, J.T. Araújo Filho ${ }^{2 B}$, R.F. Figueira ${ }^{3}$, K.M.G. Pacheco ${ }^{4 A}$, F.L. Silva ${ }^{4 B}$ \\ e D.S. Rodrigues ${ }^{5}$
}

\begin{abstract}
${ }^{1}$ Centro de Ciências Agrárias. Universidade Federal da Paraíba. UFPB/CCA. Areia-PB. Brasil. lucianazte@hotmail.com

2Universidade Federal de Alagoas. UFAL/CECA. Rod 104, km 85. Zona Rural de Rio Largo, CEP 57100000 Rio Largo. Alagoas. Brasil. Aangelina@ceca.ufal.br; Bhircus4@gmail.com

${ }^{3}$ FEJAL-CESMAC. Centro de Estudos Superiores de Maceió. Brasil. ricardofelippe@globo.com

${ }^{4}$ Centro de Ciências Agrárias. Universidade Federal de Alagoas. UFAL/CECA. Rio Largo-AL. Alagoas. Brasil. Akmgpacheco@ig.com.br; Bfabianezte@yahoo.com.br

${ }^{5}$ Área de Concentração Melhoramento Animal. Universidade Federal do Ceará. UFC/PCI. Fortaleza. Ceará. Brasil. daliane27@hotmail.com
\end{abstract}

\section{PALAVRAS CHAVE ADICIONAIS}

Peso ao nascer. Cabugi. Dorper. Santa Inês.

\section{RESUMO}

O objetivo deste trabalho foi avaliar cordeiros provenientes de cruzamentos e estimar alguns efeitos de ambiente que afetam o desempenho desses animais em um plantel de ovinos deslanados no Estado de Alagoas. As características estudadas foram peso ao nascer, aos 15, 30 e 45 dias de idade. Foram incluídos os efeitos de tipo de parto (simples ou múltiplos), sexo do produto, genótipo (Santa Inês (SI), Dorper x Santa Inês (DxSI), Cabugi x Santa Inês (CxSI) e Mestiço $x$ Santa Inês (MxSI)) e grupo de contemporâneos (mês e ano de nascimento) em 128 informações de parições. As médias de peso ao nascer para os cordeiros SI, D x SI, C x Sl e M x SI foram de 3,32; 3,$59 ; 2,95$ e $3,28 \mathrm{~kg}$, respectivamente. As médias de peso aos 45 dias de idade para os cordeiros $\mathrm{SI}$, D x SI, C x SI e M x SI foram 9,09; 9, 17; 10,58 e 9,08 $\mathrm{kg}$ respectivamente. $\mathrm{O}$ efeito de tipo de parto foi significativo para todas as variáveis em estudo indicando que animais oriundos de partos simples apresentaram pesos superiores na pré desmama. Os efeitos de sexo e genótipo não foram significativos para nenhumas das características. O

*Apoio financeiro da Fundação de Apoio à Pesquisa do Estado de Alagoas-FAPEAL.

Recibido: 3-5-07. Aceptado: 17-5-07.

\section{Additional KeYWORDS}

Birth weight. Cabugi. Dorper. Santa Inês.

grupo de contemporâneos foi significativo apenas para peso ao nascer.

\section{SUMMARY}

The aim of the study was to evaluate crossbred lambs and to estimate some environment effects which affect the performance of those animals in Alagoas state, Brazil. The traits studied were birth weight, weight at 15 days, weight at 30 days and weight at 45 days. In 128 calving informations, the effects of type of birth, sex of lambs, genotype and contemporary group (year, month of birth) were included. The effects of type of birth were significant for all traits studied. Animals from single birth were weighter than double birth ones. The effects of sex and genotype weren't significative for any trait. The contemporary group (year, month of birth) was significant only for birth weight.

\section{INTRODUÇÃO}

O NE brasileiro apresenta um rebanho com, aproximadamente, 9,04 milhões de cabeças de ovinos ocupando a primeira posição no contexto nacional, com $56 \%$ do

Arch. Zootec. 58 (221): 145-148. 2009. 
rebanho ovino no Brasil (Anualpec, 2005).

$\mathrm{O}$ interesse do consumidor de carne por alimentos de origem da ovinocaprinocultura tem se tornado cada vez mais evidente. Provavelmente, por conta da sua qualidade organoléptica, seu valor nutritivo e palatabilide. Apesar do elevado potencial para produção, o setor ainda não apresenta índices satisfatórios de produção em virtude do manejo inadequado, acarretando baixa eficiência dos sistemas de produção tendo como principais prejuízos o abate de animais em idades avançadas e ausência de padronização de carcaça.

Os cruzamentos visam explorar os benefícios da heterose nas características econômicas, especialmente naquelas em que a seleção individual ou massal é pouco efetiva. A prática de cruzamento em ovinos, entre uma raça especializada e uma raça adaptada pode contribuir para o aumento da eficiência dos sistemas de produção (Osório et al., 2002). A utilização de cruzamentos industriais é um dos caminhos que pode ser adotado para obtenção de maior velocidade de crescimento dos animais. De acordo com Notter (2000), o cruzamento industrial favorece a conjugação das características desejáveis de cada raça e a exploração da heterose, que é máxima na primeira geração.

Essa pesquisa teve como objetivo avaliar o desempenho de cordeiros cruzados e estimar os efeitos de sexo, tipo de parto, grupo genético, mês e ano de nascimento sobre o peso ao nascer, 15, 30 e 45 dias de idade em ovinos deslanados.

\section{MATERIAISE MÉTODOS}

A pesquisa foi realizada no Setor de Ovinocultura da Usina S/A Leão Irmão Açúcar e Álcool no período de 2005 e 2006, Zona Rural de Maceió, Alagoas, inserida na mesorregião da Zona da Mata, 50 metros acima do nível do mar, Latitude $9^{\circ} 33^{\prime} 21^{\prime \prime} \mathrm{S}$, Longitude $35^{\circ} 52^{\prime} 15^{\prime \prime} \mathrm{W}$. O clima da região é do tipo tropical chuvoso com verões secos, caracterizando-se por duas estações, uma chuvosa (maio a setembro), e outra seca (outubro a abril). A pluviosidade média anual é de $1700 \mathrm{~mm}$.

Os animais foram mantidos em regime semi-extensivo em piquetes de Brachiária decumbens, sendo recolhidos ao entardecer e pernoitando em aprisco de chão batido, onde foram fornecidos sal mineral, água e suplementação com levedura e volumosos.

Foram realizados cruzamentos por meio de monta natural e o desmame foi praticado em torno de três meses de idade. Nos cruzamentos foram utilizados carneiros das raças Santa Inês (SI), Dorper (D), Cabugi (C) e um mestiço, M, (1/8 Lacaune 1/8 Dorper 1/ 8 Somalis 5/8 Santa Inês) com fêmeas do rebanho base Santa Inês. As pesagens foram feitas ao nascer, aos 15,30 e 45 dias de idade.

As características estudadas foram peso ao nascer, $\mathrm{PN}$, aos $15, \mathrm{P}_{15}, 30, \mathrm{P}_{30}$ e 45 dias de idade, $\mathrm{P}_{45}$. Foram obtidas $164,52,47$ e 24 informações de $\mathrm{PN}, \mathrm{P}_{15}, \mathrm{P}_{30}$ e $\mathrm{P}_{45}$, respectivamente. Os dados foram analisados por meio de análise de variância utilizando-se o procedimento (GLM) do SAS (1996), empregando-se o modelo estatístico, descrito a seguir, o qual incluiu os efeitos fixos de tipo de parto (simples e múltiplos), grupo contemporâneo (mês e ano de nascimento), sexo e grupo genético (SI, $1 / 2$ D $1 / 2$ SI, $1 / 2$ C $1 / 2$ $\mathrm{SI}$ e $1 / 2 \mathrm{M} 1 / 2 \mathrm{SI}$ ).

$$
Y_{\text {Imnop }}=\mu+T_{1}+G_{m}+S_{n}+G_{o}+e_{\text {Imnop }}
$$

em que:

$\mathrm{Y}_{\text {Imnop }}=\mathrm{PN}, \mathrm{P}_{15}, \mathrm{P}_{30}$ e $\mathrm{P}_{45}$,

$\mu=$ média geral,

$\mathrm{T}_{\mathrm{I}}=$ efeito do $\mathrm{I}$-ésimo tipo de parto $(\mathrm{I}=$ simples e duplos),

$\mathrm{GC}_{\mathrm{m}}=$ efeito do m-ésimo grupo de contemporâneo (200503, 200504, 200505, 200506, 200507, 200601, 200602, 200612),

$\mathrm{S}_{\mathrm{n}}=$ efeito do n-ésimo sexo do produto (macho e fêmea),

$\mathrm{G}_{0}=$ efeito do o-ésimo grupo genético (SI, $1 / 2 \mathrm{D}$ 1/2 $\mathrm{SI}, 1 / 2 \mathrm{C} 1 / 2 \mathrm{SI}$ e $1 / 2 \mathrm{M} 1 / 2 \mathrm{SI}$ ),

$\mathrm{e}_{\text {Imnop }}=$ erro aleatório associado a cada observação, pressuposto normalmente distribuído com média zero e variância $\sigma^{2}$. 


\section{RESULTADOSEDISCUSSÃO}

Os efeitos de tipo de parto e grupo de contemporâneo foram significativos $(\mathrm{p}<0,01)$ e $(\mathrm{p}<0,05)$ para PN. As médias de tipo de parto para PN foram 3,43 e 2,93 kg, para partos simples e duplos, respectivamente. Fêmeas de partos simples apresentaram superioridade de $17,06 \%$ no PN. Cordeiro et al. (2004) mostraram superioridade de $24,66 \%$ do PN em partos simples comparado ao PN em parto duplos. Geralmente, matrizes com incidência de partos múltiplos, sem manejo apropriado, apresentam média de peso ao nascimento inferior.

O tipo de parto apresentou reflexos nos primeiros meses de vida do animal, pois também foi significativo para $\mathrm{P}_{15}(\mathrm{p}<0,01)$, $\mathrm{P}_{30}(\mathrm{p}<0,05)$ e $\mathrm{P}_{45}(\mathrm{p}<0,05)$. As pesagens do animal aos 15,30 e 45 dias foram significativamente superiores para partos simples. Resultados semelhantes foram encontrados por Quesada et al. (2002) num estudo com ovinos deslanados no planalto central Brasileiro.

O efeito de sexo, como em Cordeiro et al. (2004) e Fraga et al. (2003), não foi causa de variação importante para as características em estudo. Por outro lado, vários trabalhos têm demonstrado a superioridade dos machos na habilidade em ganhar peso com relação às fêmeas, dentre eles podem ser citados Quesada et al. (2002) e McManus e Miranda (1997).

O genótipo do cordeiro não foi significativo para nenhuma característica em estudo. É provável que a idade em que os animais foram avaliados ainda não tenha sido possível a manifestação de vigor híbrido dos grupos genéticos envolvidos nesta pesquisa.

As médias ajustadas e desvios padrão para peso ao nascer foram $3,04 \pm 0,10 ; 3,36$ $\pm 0,22 ; 2,99 \pm 0,13$ e $3,32 \pm 0,12 \mathrm{~kg}$, para os cordeiros SI, D x SI, C x SI e M x SI, respectivamente. Os valores médios de peso ao nascer, obtidos na presente pesquisa, foram próximos àqueles apresentados por $\mathrm{McMa}$ nus e Miranda (1997), os quais foram 3,70 e $3,55 \mathrm{~kg}$, para as raças Bergamácia e Santa Inês, respectivamente. Foram também semelhantes aos valores médios relatados por Quesada et al. (2002) para raças Morada Nova, Santa Inês e mestiços Texel x Morada Nova, cujos valores foram 2,36; 3,07 e 2,84 $\mathrm{kg}$, respectivamente.

As médias de $\mathrm{P}_{30}$ foram 7,18 $\pm 0,62 ; 6,42$ $\pm 0,43 ; 6,93 \pm 0,53 ; 6,36 \pm 0,51 \mathrm{~kg}$ para os cordeiros SI, D x SI, C x SI e M x SI, respectivamente. Esses valores foram próximos àqueles observados por Quesada et al. (2002), os quais foram 5,54 kg, 8,01 kg e 7,53 $\mathrm{kg}$ para animais dos grupos Morada Nova, Santa Inês e Texel x Morada Nova, aos 30 dias de idade, respectivamente. Esses autores observaram que a superioridade dos mestiços só foi revelada a partir de 120 dias de idade e, aos 30 dias a raça Santa Inês apresentou melhor desempenho. Os autores ainda afirmam que esse fato pode ter ocorrido por conta da elevada habilidade de produção de leite dos animais Santa Inês. Entretanto, cordeiros cruzados por ocasião da permanência no pasto manifestam maior potencial na velocidade de ganho de peso. Por outro lado, Bianchi et al. (2003) verificaram superioridade $(\mathrm{p}<0,05)$ do peso ao nascer de 10 a $13 \%$ em cordeiros oriundos de cruzamentos de carneiros Sufollk e Milchaschaf com ovelhas Corriedale.

Com relação ao peso aos 45 dias de idade as médias obtidas foram 9,09 $\pm 3,0 ; 9,17 \pm$ 1,$47 ; 10,58 \pm 1,65$ e $9,08 \pm 1,66 \mathrm{~kg}$, respectivamente, para os grupos SI, D x SI, C x SI e $\mathrm{M} \times \mathrm{SI}$. Esses valores foram inferiores quando comparados com o peso aos 45 dias em animais da raça Churra Badana, em um estudo conduzido por Carolino et al. (2004), cuja média foi estimada em 12,95 $\pm 2,23 \mathrm{~kg}$.

Embora neste trabalho, o efeito do genótipo não tenha sido significativo, animais do grupo Cabugi $x$ SI apresentaram baixo peso ao nascimento, mas o peso aos 45 dias de idade foi o grupo de maior expressão. Resultados como esses demonstram o potencial das raças locais na 


\section{ROCHA, FRAGA, ARAÚJO FILHO, FIGUEIRA, PACHECO, SILVAE RODRIGUES}

habilidade em ganhar peso na pré-desmama. Ao contrário do que se esperavam, cordeiros com $50 \%$ de genes oriundos de raças locais apresentaram desempenho igual ou superior aos grupos envolvendo genes de raças especializadas. Além da importância do estudo do potencial de produção dos recursos genéticos locais, cabe ressaltar que para exploração dos benefícios da heterose é indispensável à existência de grupos genéticos distintos, com características e peculiaridades próprias, para possibilitar a complementaridade entre raças e a máxima expressão da heterose.

$\mathrm{O}$ efeito de grupo contemporâneo foi significativo apenas para o peso ao nascer. Os resultados mostraram valores superio-

\section{BIBLIOGRAFIA}

Anualpec. 2005. FNP Consultoria \& Comércio. São Paulo. p. 350-351.

Bianchi, G., G. Garibotto e O. Bentancur. 2003. Características de crecimiento de corderos ligeros hijos de ovejas Corriedale y Moruecos Corriedade, Texel, Hampshire Down, Southdown, lle de France, Milchschaf O Suffolk. Arch. Zootec., 52: 339-345.

Carolino, N., S. Lopes e L. Gama. 2004. Consangüinidade e depressão sanguínea num efectivo ovino da raça Churra Badana. Arch. Zootec., 53: 229-232.

Cordeiro, C.F.A., J.T. Araújo Filho, A.B. Fraga, C.C.F. Silva, M.J.M. Santos e E.C. Miranda. 2004 Peso ao nascer, escore corporal à cobertura, ao parto em ovinos Santa Inês, na região Agreste do Estado de Alagoas. Em: VI Congresso Internacional de Zootecnia. IX Congresso Nacional de Zootecnia, Brasília-DF.

Fraga, A.B., A.A. Braga, F.M.H. Cavalcanti, J.T. Araújo Filho, M.C. Queiroz e O. Souza. 2003. Peso ao nascer e ao desmame em ovinos da raça Santa Inês no Vale do Paraíba, Estado de res para nascimentos em dezembro, janeiro e fevereiro. Provavelmente, por que as ovelhas que pariram nessa época tiveram a gestação num período não muito desfavorável com relação à disponibilidade de alimentos.

\section{CONCLUSÕES}

Cordeiros da raça Santa Inês e cruzados apresentaram peso ao nascimento e desempenho na pré-desmama semelhantes.

Cordeiros oriundos de partos simples apresentaram melhores desempenhos no nascimento e na pré desmama.

O desempenho para peso ao nascer e peso na pré desmama foi semelhante entre cordeiros machos e fêmeas.

Alagoas. Em: 40 Reunião Anual da Sociedade Brasileira de Zootecnia. Santa Maria, RS.

McManus, C. e R.M. Miranda. 1997. Comparação das raças de ovinos Santa Inês e Bergamácia no Distrito Federal. Rev. Bras. Zootecn., 26: 1055-1059.

Notter, D.R. 2000. Development of sheep composite breeds for lamb production in the tropics. 2000. In: Simpósio Internacional sobre Caprinos e Ovinos de Corte, 1., João Pessoa. Anais. EmepaPB. João Pessoa. p. 141-150.

Osório, J.C.S., N.M. Oliveira, M.T.M. Osório, R.D. Jardim e M.A. Pimentel. 2002. Produção de carne em cordeiros Cruza Border Leicester com ovelhas Corriedale e Ideal. Rev. Bras. Zootecn., 33: 1048-1059.

Quesada, M., C. Mcmanus e F.A.D. Couto. 2002. Efeitos genéticos e fenotípicos sobre características de produção e reprodução de ovinos deslanados no Distrito Federal. Rev. Bras. Zootecn., 31: 342-349. Suplemento.

SAS. 1996. User's Guide: Statistics, Version 6.11. SAS Institute, Inc. Cary, NC. 